\title{
INTERCULTURALIDADE CRÍTICA: APRENDER A DECOLONIZAR A EDUCAÇÃO COM SABERES DE MULHERES RIBEIRINHAS DA AMAZÔNIA
}

Isabell Theresa Tavares Neri ${ }^{\mathrm{i}}$ Ivanilde Apoluceno de Oliveirai

\begin{abstract}
Resumo: Neste artigo analisa-se os saberes de mulheres em tratamento hospitalar, vítimas de escalpelamento nos rios da Amazônia ou acompanhantes, e que frequentam, em um espaço de acolhimento, uma classe hospitalar. Este estudo consiste em um recorte de uma pesquisa, concluída em 2018, financiada pela FAPESPA, realizada em um ambiente hospitalar, em que se desenvolve uma educação intercultural crítica freireana, que fomenta o empoderamento das mulheres ribeirinhas por meio do reconhecimento de suas vozes, saberes, práticas e manifestações culturais. É uma pesquisa de campo qualitativa com os seguintes procedimentos metodológicos: levantamento bibliográfico e documental, entrevistas com 15 mulheres de faixas etárias variadas, oriundas de diferentes comunidades ribeirinhas da Amazônia Paraense e observação participante. Entre os resultados destaca-se que a aprendizagem se dá por meio de narrativas das mulheres sobre o "enfrentamento da violência de gênero", o "trabalho", a "medicina popular" e o "imaginário", que fazem parte do contexto de diversidade biossocial e cultural das comunidades ribeirinhas da Amazônia.
\end{abstract}

Palavras-chave: Interculturalidade crítica; Decolonizar a educação; Mulheres ribeirinhas.

\section{CRITICAL INTERCULTURALIDADE: LEARN TO DECOLONIZE THE EDUCATION WITH RIVERSIDES WOMEN'S KNOWLEDGES OF THE AMAZON}

\begin{abstract}
In this article it is analyzed the women's knowledge in hospital treatment, victims of the scalping in Amazon rivers or accompanying, and participating in a foster home, hospital class. This study consists of a cutting of a research, finished in 2018, funded by FAPESPA, realized in a hospital, in which training develops a intercultural criticism freireana education that stimulates the riverside women empowerment through the recognition of their voices, knowledge, practices and cultural manifestations. This a field qualitative research of the following methodological procedures: bibliographical and documentary survey, interview with 15 women of all ages, from the different riversides communities of the Para Amazon and participant observation. Between the results stand out that learning happens by way through the use of narratives of female about the confrontation of gender violence, the work, the popular medicine and imaginary are part of the context of biosocial diversity and cultural of Amazonian riverside communities.
\end{abstract}

Keywords: Critical Interculturality; Decolonize the Education; Riverside women. 


\section{Introdução}

Neste artigo analisa-se os saberes de mulheres em tratamento hospitalar, vítimas de escalpelamento nos rios da Amazônia ou acompanhantes, e que frequentam, em um espaço de acolhimento, uma classe hospitalar. Saberes oriundos de práticas cotidianas sociais em comunidades ribeirinhas da Amazônia Paraense e que expressam um aprendizado de vida e de mundo.

Este estudo consiste em um recorte de uma pesquisa, concluída em 2018, financiada pela FAPESPA, realizada na classe hospitalar em que se desenvolve uma educação intercultural crítica freireana, envolvendo a Secretaria de Estado de Educação e um Núcleo de Educação Popular de uma Universidade pública do Estado do Pará.

Paulo Freire na elaboração do seu pensamento educacional, traz para debate a interculturalidade crítica. Reflete sobre as diferenças, em uma dimensão política, afirmando terem cortes de classe, raça, gênero e nações, sendo necessário compreendê-las em suas relações históricas e culturais, como processo de opressão social e de poder. Assim, denuncia as diversas e específicas formas de opressão vigentes na sociedade e anuncia, por meio da criação de estruturas coletivas, a possibilidade de libertação.

No processo educacional realizado no ambiente hospitalar valoriza-se a cultura local de origem destas mulheres, bem como suas práticas, saberes e experiências de vida.

Compreende-se que a cultura está presente em todas as dimensões da sociedade, como um conjunto complexo e diferenciado de teias - de símbolos e significados - com as quais homens e mulheres criam entre si e para si mesmos sua própria vida social (BRANDÃO, 1995, p. 86). E a cultura ribeirinha, segundo Loureiro (1995), é uma das mais representativa da cultura amazônica, pelos traços de originalidade expressa pela criatividade de sua população e o produto de suas experiências sociais, cujas raízes são indígenas e caboclas.

Além disso, ao nosso ver, o acidente que as mulheres sofrem por falta de serem cobertos os motores dos barcos, não está dissociado de questões de raciais e de gênero. As maiores vitimas de escalpelamento na Amazônia Paraense são as mulheres negras e pardas.

A questão racial e a de gênero, então, fazem parte da educação intercultural crítica realizada no ambiente hospitalar, que possibilita estudar a forma de compreender o mundo relacionadas à concepção de "bem-viver" com a natureza, de uma população de mulheres 
originária do hemisfério sul. Constitui uma educação crítica que fomenta o empoderamento das mulheres ribeirinhas por meio do reconhecimento de suas vozes, saberes, práticas e manifestações culturais.

Este artigo está organizado em três partes: a primeira apresenta-se os fundamentos e procedimentos metodológicos da pesquisa; a segunda, os aportes teóricos da decolonialidade do saber e da educação intercultural crítica de Paulo Freire e a terceira, o aprender a decolonizar a educação, com os saberes das mulheres, vítimas de escalpelamento, de comunidades ribeirinhas da Amazônia Paraense.

\section{Fundamentos e procedimentos metodológicos}

Consiste em uma pesquisa de campo qualitativa, que segundo Lüdke e André (1986), é responsável por provocar um "borramento de fronteiras"iii entre as áreas de conhecimento e está intimamente relacionada à eclosão dos movimentos sociais sobretudo na década de 1960 que estimularam investigações, especialmente no campo da educação, dispostas a se divorciar da lógica positivista e da dicotomia entre o sujeito e o objeto de estudo.

Pesquisa financiada pela Fundação Amazônia Paraense de Amparo à Pesquisa FAPESPA, realizada nos anos de 2017 e 2018, em uma classe hospitalar, com 15 mulheres de faixas etárias variadas, oriundas de diferentes comunidades ribeirinhas da Amazônia Paraense.

Neste artigo, apresenta-se o relato de seis das educandas entrevistadas, que residem nos municípios de Breves, São Sebastião da Boa Vista, Viseu, Itaituba, Fordlândia e Porto de Moz. Com o objetivo de preservar as suas identidades, foram adotados os seguintes nomes fictícios: Ceuci, Aracy, Amanacy, Iara, Juruti e Angra, sendo as três primeiras acompanhantes e as três últimas em tratamento médico por conta do escalpelamento.

A Cartografia dos saberes se constitui uma estratégia metodológica, cujo objetivo é contribuir para o mapeamento de traços da história e da cultura das comunidades ribeirinhas, mantidos pela comunicação oral, mas sem registro (OLIVEIRA, 2008, p. 16). As suas bases teóricas estão em Santos (2002), que compreende a cartografia simbólica como um modo de 
imaginar e representar a realidade social e em McLaren (1991) que utiliza o termo cartografia cultural, com o sentido de delinear significados manifestos em encontros pedagógicos.

Os procedimentos metodológicos utilizados foram: levantamento bibliográfico e documental, sendo que o primeiro corresponde à literatura científica responsável por fomentar o diálogo com os dados coletados, enquanto que o segundo se caracteriza pela leitura de documentos que ainda não receberam um tratamento analítico, como os planos de aula e os relatórios correspondentes às atividades educativas (RODRIGUES; FRANÇA, 2010). Entrevista semiestruturada realizada com 15 mulheres, frequentadoras da educação de jovens e adultos na perspectiva freireana, na classe hospitalar e observação participante. Os questionamentos deste tipo de entrevista viabilizam a criação de novas hipóteses a partir das respostas dos sujeitos da pesquisa, sendo responsável por uma descrição mais detalhada sobre os fenômenos sociais (TRIVIÑOS, 1987).

A observação participante, segundo Queiroz et al (2007, p.277), torna-se uma técnica científica a partir do momento em que passa por sistematização, planejamento e controle da objetividade, ou seja, o/a pesquisador/a apura o seu olhar para a realidade investigada.

Os cuidados éticos foram realizados por meio da aprovação da pesquisa no Comitê de Ética, da não identificação dos sujeitos, o uso do Termo de Consentimento Livre e Esclarecido, entre outros.

A sistematização e análise dos dados foi realizada por meio de categorizações temáticas, constituídas por indicadores de análise, ou seja, fatores, aspectos, elementos do fato ou situação em estudo, que são classificados e reunidos em eixos ou unidades temáticas a partir e com os dados coletados (OLIVEIRA, MOTA NETO, 2011, p.164).

As narrativas das mulheres educandas ribeirinhas, para este artigo, estão focadas em quatro categorias temáticas: "o enfrentamento da violência de gênero", o "trabalho", a “medicina popular" e o "imaginário", considerando o contexto de diversidade biossocial e cultural das comunidades ribeirinhas da Amazônia.

\section{Aportes teóricos}

Oliveira (2015) explica que a multiculturalidade é concebida por Paulo Freire em uma perspectiva crítica, situada no processo de libertação, cujos fundamentos são a consciência 
crítica, o respeito à diferença de cada cultura e na possibilidade de crescerem juntas, por meio de uma relação que é tensa, mas pode ser dialógica. Freire compreende a multiculturalidade como um processo em construção, uma criação histórica, que implica vontade, decisão política, mobilização e organização dos grupos sociais visando fins comuns. Destaca, ainda, a autora que Freire defende a tese da unidade na diversidade, como necessária para a luta política contra todas as formas de opressão, seja por fatores de classe, etnia, gênero, entre outras. Em suas obras refere-se à questões de classe, gênero, etnia, colonialismo, entre outras.

Freire discute o colonialismo ao realizar crítica ao processo opressor $d a$ colonização, no qual o dominante realiza a invasão cultural, impõe a cultura do silêncio e obstaculiza a participação democrática (OLIVEIRA, 2015, p.). Ele problematiza a colonização, denunciando:

A presença predatória do colonizador, seu incontido gosto de sobrepor-se, não apenas ao espaço físico mas ao histórico e cultural dos invadidos, seu mandonismo, seu poder avassalador sobre as terras e as gentes, sua incontida ambição de destruir a identidade cultural dos nacionais, considerados inferiores, quase bichos, nada disto pode ser esquecido quando, distanciados no tempo, corremos o risco de "amaciar" a invasão e vê-la como uma espécie de presente "civilizatório" do chamado Velho Mundo. Minha posição hoje, decorridos 500 anos da conquista [...] é a de quem não se acomoda diante da malvadeza intrínseca a qualquer forma de colonialismo, de invasão de espoliação (FREIRE, 2000, p. 73-74).

É importante destacar a crítica que Paulo Freire (2001) faz à mentalidade colonizadora no Brasil, que se caracteriza pelo autoritarismo, pela acriticidade e pela não participação de segmentos sociais na vida pública. Freire explica que a imposição da cultura europeia aguçou a opressão dos escravos e servos, dos africanos e indígenas, bem como importou o modelo de educação jesuítica, sem relação com o contexto sociocultural brasileiro.

Na África, Freire (1978) destaca que o objetivo da educação colonialista era a desafricanização dos nativos, por meio do discurso ideológico da superioridade branca e pela manutenção da cultura dos colonizadores. Por isso, compreende que a luta política no campo educacional pressupõe o "descolonizar as mentes" ou "reafricanizar as mentalidades", tendo como ponto de partida as culturas nativas, com o objetivo de firmar a identidade cultural das 
mesmas e superar as estruturas de poder colonialistas e eurocêntricas. Isto significa reconhecer e valorizar os seus saberes culturais.

A crítica de Freire ao colonialismo consiste, então, ao processo de dominação e opressão que sofrem os povos colonizados, sendo criada uma mentalidade colonizadora, que mantém o discurso é de superioridade dos dominadores e de inferioridade dos colonizados, configurando-se em um processo de subalternização política, econômica, racial, linguística, epistêmica, entre outras.

Para Dussel (1992) o descobrimento da América foi tanto o acontecimento fundante da modernidade, como inicia a relação de dominação colonialista, ao conquistador negar e encobrir o outro, o índio, em sua alteridade, considerado inculto, bárbaro, etc.

A cultura europeia na visão de Dussel (1992) se apresenta como a mais desenvolvida e superior a outras culturas não-europeias, constituindo-se em um discurso eurocêntrico e um "mito da modernidade", porque oculta o processo de "dominação" ou "violência" que exerce sobre outras culturas, legitimando o discurso de superioridade-inferioridade e a violência do conquistador e o sofrimento do conquistado interpretados como um custo necessário ao processo de modernização. Assim, apesar do fim do colonialismo, a colonialidade permanece, ou seja, as estruturas subjetivas, os imaginários e a subordinação epistemológica e política da colonização.

Quijano (2007) define como colonialidade do poder a que impõe os saberes e imaginário simbólico do colonizador reprimindo os saberes e imagens do colonizado, naturalizando a sua superioridade e a subordinação epistêmica e política do outro.

Neste debate epistemológico, Santos (2010) explica que o pensamento moderno é abissal, isto é, cria um abismo epistemológico entre os saberes, legitimando e visibilizando o saber científico moderno e negando e inviabilizando os saberes das culturas não-europeias. Ele, então, designa a diversidade epistemológica do mundo como "Epistemologias do Sul", que constituem intervenções epistemológicas, que tanto denunciam a supressão de saberes próprios dos povos colonizados como valorizam esses saberes e buscam estabelecer uma ecologia dos saberes, promovendo a interação entre os diferentes saberes. 
Desta forma, configura-se como uma luta política pelo reconhecimento dos sujeitos e de uma episteme no saber dos sujeitos de culturas não-europeias, historicamente negadas, bem como, implica em um aprender com o outro, anteriormente visto sem ter nada para ensinar.

Para Paulo Freire:

aprender e ensinar fazem parte da existência humana, histórica e social, como dela fazem parte a criação, a invenção, a linguagem, o amor, o ódio, o espanto, o medo, o desejo, a atração pelo risco, a fé, a dúvida, a curiosidade, a arte, a magia, a ciência, a tecnologia. E ensinar e aprender cortando todas estas atividades humanas (FREIRE, 1993, p. 19).

Como atividade humana o ensinar de forma democrática implica em saber escutar. Para Freire (2007, p. 113) "somente quem escuta paciente e criticamente o outro, fala com ele, mesmo que em certas condições precise falar a ele". Isto significa que a escuta do outro possibilita ensinar e aprender com o outro, em diálogo com o outro.

\section{O aprender a decolonizar a educação com os saberes de mulheres de comunidades ribeirinhas da Amazônia Paraense}

As narrativas das mulheres ribeirinhas em torno de quatro temas: "enfrentamento da violência de gênero", "trabalho", "medicina popular" e "imaginário" se apresentam como uma cartografia de saberes, que se desenha a partir de suas vivências e práticas sociais no contexto de comunidades ribeirinhas, que envolve a terra, a mata e os rios da Amazônia.

\section{a) $O$ aprender com as mulheres ribeirinhas sobre o enfrentamento da violência de gênero}

As mulheres ribeirinhas em suas narrativas explicam as dificuldades e as violências vivenciadas em múltiplos aspectos de suas vidas para conseguirem ter acesso ao estudo.

meu tio foi em casa e perguntou se o meu irmão não queria ir com ele e o meu irmão falou que não [e] aí eu quis ir. Porque eu era louca, eu queria muito estudar e ser professora de criança. Eu fui para estudar e o meu tio foi e me levou só que foi diferente; não foi o que ele falou 
para a minha mãe [...]. Eu nunca sai do ABC porque ele é analfabeto. E aí eu dizia a lição para ele, mas ele não conhecia. Era preciso a mulher dele, que era professora, dizer para ele: "está certo, ela tem razão. Essa menina sabe". "Mas ela vai estudar mais esse ano, ele dizia." Ele chegava com a minha professora e dizia para ela não me passar, para eu estudar mais um ano na mesma série, a alfabetização. E eu ficava. Os anos que eu passei na casa dele foram só estudando o ABC [...]Antigamente, já viu. Era o homem que mandava. Se ele dissesse isso, era isso. Aí foi assim [grifo nosso] (AMANACYFORDLÂNDIA, 2018).

Nos interiores da Amazônia, o predomínio da cultura patriarcal garante aos homens a primazia pelo direito ao estudo. As mulheres, por outro lado, são cerceadas do direito de aprender a ler e a escrever o que exige delas uma grande persistência para romperem com os tabus contra o aprender das mulheres, como o exemplo de Amanacy, que levada pelo sonho de ser professora resolve aceitar a proposta de seu tio, recusada por seu irmão, para obter a oportunidade de se matricular em uma escola.

Consequentemente, o desejo de se alfabetizar esbarra no machismo do tio. A figura masculina lidera as hierarquias familiares no território amazônico constituindo um dos principais obstáculos para que Amanacy avance nos estudos.

Para Lima, há uma nítida opressão que:

pesa sobre a mulher [sobretudo latina], não somente no nível erótico, mas também no pedagógico e político. A injustiça erótica (a mulher como objeto sexual) se estende na injustiça pedagógica (a menina castrada) e na injustiça política (a mulher com salários menores do que os dos homens) [grifo nosso] (LIMA, 2016, p.84).

Podemos entender a resistência do tio de Amanacy em reconhecer o seu bom desempenho na escola como uma tentativa de mantê-la sob o seu controle. Ele segue uma lógica patriarcal, a educação para uma mulher ribeirinha deve ser limitada, senão, aos olhos mais conservadores, pode se tornar um instrumento de transgressão. E assim, nos subterrâneos de uma clássica família regida pelo patriarcado, Amanacy sofreu a violência pedagógica de repetir várias vezes o mesmo ano, ainda que o seu empenho educativo fosse 
exemplar. Uma violência que acenava para o objetivo de acorrentá-la em uma perversa condição tutelada e que a empurrará para uma infância e uma juventude sofrida.

Eu sai de casa muito nova, com 13 anos. Eu fui morar com um homem. Ele tinha mais de 40 anos e eu não tinha para onde ir [...] Eu ainda vivi com ele mais de três anos. Eu tive dois filhos dele. O primeiro morreu e o outro mora em Belo Horizonte. Eu tinha 16 anos quando fui mãe [...]Ele trabalhava com mulheres solteiras. Ele trabalhava com Cabaré e eu trabalhei lá. Com 13 anos, eu tomava conta de 23 mulheres solteiras e elas todas me respeitavam e me davam conselho [...]E, quando elas vinham do garimpo, elas iam lá para casa. Elas falavam muita coisa de ruim. Tudo o que se pode imaginar, acontecia. Apanhar, umas vinham de lá todas cortadas de fio elétrico, com doença feia, curei muita menina. Apanhavam, porque não queriam aceitar o que o homem queria. Tinham umas já de idade, bem idosas, elas vinham do Ceará, do Maranhão, do Mato Grosso, elas vinham por causa do garimpo. Isso foi em 1971, para 1972. Tinha muitos garimpos como o Tabocal. Tinham umas já de idade, bem idosas, elas vinham do Ceará, do Maranhão, do Mato Grosso, elas vinham por causa do garimpo. Isso foi em 1971, para 1972. Tinha muitos garimpos como o Tabocal. Às vezes, eles [cafetões] levavam meninas, diziam que era para terem uma profissão e elas chegavam e tinham que colocar dinheiro para eles (AMANACY-FORDLÂNDIA, 2018).

A vontade de estudar levou Amanacy a sair de casa e se mudar para Itaituba. Levada mais uma vez pela promessa de conseguir se matricular em uma escola, ela, então com apenas 13 anos, acaba se relacionando um homem quase 30 anos mais velho. Uma relação que é considerada no mínimo abusiva, já que era menor de idade.

No decorrer dos encontros educativos, Amanacy relatou que sofria violências psicológicas de seu companheiro. Situação que corrobora para os riscos apontados por Maia e Barreto (2012), pelos quais a juventude feminina amazônica é exposta. Crianças e adolescentes submetidos a sistemáticas violências alcançam a maioridade com grandes dificuldades nos campos afetivos, psicológicos e sexuais e por isso se tornam mais propensas a serem sequestradas pela prostituição, pela depressão e pela dependência química.

Durante esse nefasto relacionamento, Amanacy experimentará duas gestações-sendo a primeira malsucedida- e que, somada a uma nítida exploração trabalhista em um cabaré, aumentaram o abismo entre ela e o seu sonho de ser professora. 
O seu convívio com mulheres vítimas de diferentes violências, em meio aos prostíbulos de um garimpo, aponta para uma tentativa de conscientização sobre a sua própria situação. Para ela, acompanhar de perto a violação de muitos corpos femininos a estimulava a pensar nas próprias violências vivenciadas por sua corporeidade.

Amanacy mostra que um mesmo sofrimento compartilhado por distintas mulheres constitui um importante laço pedagógico. Cada uma delas representavam espelhos para as demais que coletivamente refletiam suas dores, suas chagas e suas humilhações, mas que ao mesmo tempo era o símbolo de um importante refúgio e de resistência feminina. Arriscamos a dizer que se tratava de um feminismo latino e amazônico a germinar na erosão dos solos dourados dos garimpos.

Assim, a comovente narrativa de Amanacy se confunde com a própria história da Amazônia. Uma narração que tem como pano de fundo a década de 1970. A Amazônia, segundo Pereira (1997), nesse período é marcada pelo advento dos grandes projetos em seu território, impulsionados pelas ameaças apresentadas pelas suas abissais fronteiras e pela cobiça global sobre as suas riquezas naturais.

Vista como a mola propulsora da economia nacional, a região amazônica foi palco do processo de colonização a ela imposto.

Nas palavras de Pereira, as rodovias Transamazônica e Cuiabá Santarém materializam:

fatores de expulsão (decorrentes do processo de modernização da agricultura do Sul do país) e a disponibilidade de terras em parte da Amazônia legal deram origem a fluxos crescentes de migrantes para áreas de fronteira. Com isso, o governo foi forçado a continuar atuando na colonização, agora com o objetivo de atenuar os problemas gerados com uma crescente imigração espontânea, oriundas da região sul do Brasil (PEREIRA, 1997, p.79).

Uma intensa imigração em direção à Amazônia que, para Mathis (1995), foi impulsionada principalmente pela febre do ouro e que logo foi visto pelos olhos do governo como um importante atrativo de mão de obra e de circulação de capital.

A década de 1970 em especial atrai um coletivo predominantemente masculino, na faixa etária dos 30 anos, instruído e desejoso de se perder nos labirintos dos garimpos espalhados pela Amazônia. Além da garimpagem do ouro, uma das principais fontes de renda, 
para os posseiros, eram a venda de bebidas alcóolicas e as casas de prostituição. É assim que se desenha o tráfico de mulheres responsável por impulsionar as casas de prostituição existentes nas regiões de garimpo.

Coroacy explica que mulheres de várias idades e provenientes de muitos estados, são enganadas por promessas sedutoras de uma vida melhor.

Para Socorro e Smith:

o tráfico de mulheres não é recente na Amazônia, mas faz parte da sua história [...] estudos apontam que a ocupação histórica da região amazônica contribuiu para a formação de uma cultura permissiva à exploração da mulher, visto que as principais ações para o desenvolvimento regional se pautavam no trabalho do homem [grifo nosso] (SOCORRO e SMITH, 2017, p.84).

Esse histórico patriarcalista e machista de violência contra a mulher marcou a vida de muitas famílias na Amazônia, como narra Coroacy.

\begin{abstract}
o meu pai era assim com a minha mãe. Ele humilhava ela. Ela só saía se fosse com ele, ela não tinha liberdade para nada. E ele ainda batia nela. Ele cansou de bater na minha mãe, de ela ficar toda roxa. Eu cansei de ver a minha mãe grávida, buchudona e ele dava nela, só fazia gritar. Se nós fôssemos lá perto, ele batia em nós. Ele era muito ruim mesmo. Não podia falar ou fazer nada. Qualquer coisa, ele agredia ela. A mulher era humilhada e ele tinha a liberdade de fazer o que ele queria com ela. O meu pai, se nós fazia um mingau, a gente tinha que esfriar e levar frio para ele, porque, se levasse quente, ele provava e jogava em nós. Café, se a gente fizesse doce, se não fizesse do tipo dele amargo ou pouco amargo, se fosse doce ele jogava na nossa cara, quente. Sofria a minha mãe e nós, também (COROACY-PORTO DE MOZ, 2018).
\end{abstract}

Assim, muitas mulheres ribeirinhas são negadas em seu direito à liberdade e à autonomia, no âmbito familiar, bem como as crianças tem as suas infâncias roubadas, por sofrerem o impedimento de viverem a infância, a curiosidade inocente e o brincar. Entretanto, há um enfrentamento à violência de gênero pelas mulheres ribeirinhas, que buscam superar a opressão do machismo, por meio de atividades de trabalho e na produção de saberes, entre os quais da medicina popular e o imaginário amazônico, além da luta pelo direito de estudar. 


\section{b) $\mathrm{O}$ aprender com o trabalho das mulheres ribeirinhas}

As mulheres nas comunidades ribeirinhas realizam diferentes tipos de trabalhos: roça, pesca, agricultura, entre outros.

Em relação ao trabalho agrícola Iara relata:

produzimos a mandioca, o arroz, o milho. Para preparar a terra, tem que derrubar, esperar secar o pau [galhos de árvores]. Depois, toca fogo, depois vai plantar a maniva. Tira a mandioca e faz a farinha. A casa de farinha é o forno, tem o motor, porque agora usa o motor para serrar a mandioca e tem a prensa para tirar o tucupi e fica a massa para poder torrar e fazer a farinha. Os adultos, que dão conta, é que torram a farinha (IARA-BREVES, 2018).

A pluralidade é uma das principais marcas da agricultura ribeirinha. A produção de diferentes espécies de frutas, legumes e tubérculos garantem a saúde e a fertilidade do solo amazônico. Iara cita três alimentos produzidos em seu roçado: o arroz, o milho e a mandioca. Essa última se destaca pela sua versatilidade gastronômica, bem como pelos saberes ancestrais que o seu cultivo engloba.

As etapas referentes ao preparo do solo para receber a maniva ${ }^{\text {iv }}$, ricamente descritas por Iara, corresponderem à coivara. Uma técnica indígena milenar que além de fortalecer a terra com nutrientes, mostra que as terras amazônicas não se adaptam à monocultura (ALVES, 2001).

$\mathrm{O}$ cultivo da mandioca, também, se destaca pela versatilidade. As riquezas culturais amazônicas se manifestam a partir do momento em que um único tubérculo proporciona um legue de artigos alimentares como, por exemplo, a tapiocav ${ }^{\mathrm{e}}$ o tucupi ${ }^{\mathrm{vi}}$.

Neste trabalho observa-se uma organização e uma lógica extremamente maturadas por parte das comunidades ribeirinhas, evidenciada pela preocupação em relegar às pessoas mais experientes as tarefas consideradas nocivas, como o torrar da farinha de mandioca em fornos de grandes dimensões, ainda que as crianças não estejam isentas dos processos de ensino e de aprendizagem que circulam pelo roçado.

Esse aprendizado de saberes oriundos do cotidiano na produção da farinha é destacado por Juruti.

Eu fiquei na casa de farinha. Eu acho que quando a gente aprende a falar na roça, já aprende a descascar a mandioca. Não sei como eu sei. É uma 
coisa que é bem precoce, mesmo. Porque, os pais estão ali trabalhando e a gente está conversando com eles bem criancinha, mesmo (JURUTIITAITUBA, 2018).

Juruti decifra as experiências pedagógicas na casa de farinha como atos espontâneos semelhantes ao desenvolvimento da fala, em um aprendizado de relações interpessoais e de saber-fazer culturais.

Concordamos com Geertz (1989) que a cultura é um ingrediente indispensável para o desenvolvimento da mente, ou seja, ao mesmo tempo em que os seres humanos expandem o seu universo cultural, ampliam também as suas cognições.

Paulo Freire (1981) lembra que mulheres e homens, conscientes de que são inacabados/as aprendem em meio às relações sociais a realizarem o compartilhamento de saberes. Assim, ao nos reportarmos às relações intergeracionais que se retroalimentam no seio do trabalho agrícola ribeirinho, a cultura da conversa se destaca.

Segundo Oliveira e Mota-Neto (2008, p. 73) cultura da conversa, corresponde ao saber experiencial apreendido no cotidiano social, através da oralidade. A conversa é um importante elo de ligação entre diferentes saberes e experiências em meio às relações inter geracionais. A oralidade apresenta-se como a forma típica das populações rurais-ribeirinhas de expressarem suas vivências, transmitem seus saberes, valores e hábitos das gerações mais antigas às gerações mais novas, o que permite o enraizamento de uma cultura de conversa.

Esta conversa pedagógica presente nas casas de farinha demonstra ser este espaço educativo, preservando as tradições, memória, valores e visão de mundo originalmente cabocla (OLIVEIRA, MOTA-NETO; SOUZA, 2007), bem como palco de outras pedagogias, na maioria das vezes invisibilizadas no contexto escolar.

Uma sabedoria cosmogônica está presente no relato da educanda Juruti sobre a plantação do abacaxi.

A gente planta o abacaxi quando o céu está limpo. Quando não tem aquela mistura de nuvens, se as nuvens estiverem misturadas, quando olhar, o abacaxi vai estar todo empedrado. Quando o céu está limpo, a planta fica hidratada e para evitar muito bicho que dá (ARACY-SÃO SEBASTIÃO DA BOA VISTA, 2018). 
O relato de Juruti reforça a leitura do roçado como um espaço educativo. A sua narrativa demonstra ter conhecimentos sobre meteorologia, botânica e biologia obtidos na prática do trabalho na roça. Uma visão interdisciplinar maturada a partir das relações com a natureza, em que a floresta se torna um laboratório a céu aberto de experiências e vivências, responsáveis por levar a epistemologias outras que não estão presentes nos livros didáticos.

Esses conhecimentos adquiridos no saber-fazer das práticas sociais não são memorizados, mas sim compreendidos e sistematizados, sendo indispensáveis para a própria sobrevivência das comunidades ribeirinhas.

Sobre a extração do açaí, Angra descreve:

eu já trabalhei muito com açaí, tirando mesmo o açaí para mim vender e subindo na árvore [...] a peconha ${ }^{l}$ a gente faz de saca de trigo e ela é segura. Tem que dar um bom nó nela. Mas, não pode ser qualquer nó. Tem que amarrar a primeira e a segunda vez, cada uma de um lado. Tem que saber o tipo de nó. Depois, vai lá em cima, corta, tira o casco e tem que debulhar. Eu sou toda cheia de corte de tanto trabalhar com o açai e de pegar palmito (ANGRA-VISEU, 2018).

Nos saberes edificados pelas mulheres nas comunidades ribeirinhas a consciência ambiental tem prioridade. Restos de materiais que costumam ser despejados em esgotos e em lixões a céu aberto nas grandes megalópoles, ganham um destino diferente nos territórios onde habitam os povos da floresta. Uma simples saca de farinha se transforma, por meio da criatividade ribeirinha, em um importante instrumento de trabalho para a coleta do açaí: a peconha. O que aparentemente se apresenta como um utensílio simples, na verdade é fruto de uma inteligência criativa ribeirinha, diante dos desafios encontrados para confeccionar a peconha na coleta do açaí.

A confecção da peconha, então, dispensa cálculos matemáticos ou conceitos sobre mecânica; a elaboração deste instrumento é possibilitada pelas vivências laborais das mulheres ribeirinhas. A prática destas mulheres ainda contraria o próprio discurso biológico

\footnotetext{
${ }^{1}$ Círculo formado por saco de aniagem, corda ou folha de açaí, onde o ribeirinho coloca seus pés e os prende no estirpe do açaizeiro (AZEVEDO, 2005, p.67).
} 
que associa a anatomia do corpo feminino a uma insana fragilidade física. Elas desenvolvem atividades de roça e de pesca, assim como os homens.

Hooks (1981) em um de seus livros realiza uma brilhante provocação: e não sou uma mulher? Ao vivificar a memória de tantas mulheres não brancas que sempre tiveram que realizar atividades "consideradas masculinas" para poderem sobreviver.

A Iara no seu relato descreve tanto o aprendizado dos utensílios da pesca quanto sobre os tipos de peixes mais fáceis ou difíceis de pescar nos rios da Amazônia.

A gente faz tanto a roça quanto a pesca. Usamos muito a malhadeira, o anzol, o espinhão e o anzol colocado em uma linha-linha de arraste e coloca umas plantas do mato que eu não sei o nome e vai arrastando no casco ou na rabeta, mesmo. A malhadeira é colocada. Faz um círculo e sai cutucando com a vara dentro. Também pode amarrar em uma vara e espera. A malhadeira são o meu pai e meus irmãos que fazem. É uma linha própria que eles compram para entralhar que eles falam, amarra uma vara encima e outra embaixo e coloca umas boias, para não afundar. Tem pesca que corta uma isca e coloca no espinhel estica no rio e deixa lá a noite inteira e de manhã vai ver. Pegamos muito filhote e Tucunaré. Os mais dificeis são pescada branca, surubim, uns compridos, que têm uma escama grandona, o Aruanã. São os mais dificeis de encontrar (IARA-BREVES, 2018).

Assim, os rios se apresentam como outro importante palco de atuação para as mulheres ribeirinhas. A prática da pesca tanto satisfaz uma necessidade fisiológica, como estimula experiências criativas que retroalimentam a cultura ribeirinha.

Sem dúvida, os rios desafiam a curiosidade das pescadoras ribeirinhas que se tornam pesquisadoras com o ofício da pesca. Observam e são desafiadas a intervir no cenário amazônico. Conhecer as espécies aquáticas não está apenas ligado aos hábitos alimentares, mas também à edificação de uma engenharia de pesca costurada a partir dos saberes populares, que são capazes de catalogar e denominar peixes de tamanhos, cores e formas variados e que transcendem a própria prática pesqueira.

\section{c) A medicina popular pelas vozes das mulheres ribeirinhas}

$\mathrm{O}$ viver das mulheres nos rios e nas matas da Amazônia as fazem elaborar uma medicina popular, com remédios e terapias milenares passadas de geração para geração, contribuindo para a conservação da natureza e da valorização dos animais, das ervas, dos 
matos, frutos e árvores do contexto amazônico. Distantes das grandes cidades, dos hospitais, das farmácias e dos médicos, bem como a necessidade do cuidar do corpo e de manter a vida, faz com que seja produzida a medicina popular com os recursos da natureza.

E essa medicina popular, por meio de remédio caseiro, foi utilizada pelas mulheres no tratamento do couro cabeludo, lesionado no escalpelamento, conforme o relato de Amanacy.

A minha mãe fazia a banha da sucurijú, ela fazia mastruz, ou o pó ou o sumo com sulfa e passava na minha cabeça [lesionada pelo escalpelamento]. Eu sou muito mais o remédio caseiro. Ele não tem muita mistura, ele é natural, o remédio caseiro. Às vezes, eu não tinha o dinheiro para comprar o soro, e a minha mãe fazia chá travoso, com casca de caju, casca de goiaba. Ela cozinhava e ai botava no sereno, para de manhã, lavar. Com 8 meses, sarou a minha cabeça (AMANACY-FORDLÂNDIA, 2018).

A floresta amazônica, por sua diversidade cultural, constitui um centro terapêtico para as comunidades ribeirinhas, cuja produção é usada como medicamento caseiro alternativo ou associado a da medicina tradicional. No lugar do soro para lavagem do ferimento da cabeça foi utilizado o chá de casca de árvores, que tinha um processo pedagógico de elaboração, isto é, após o cozimento, ficava no sereno a noite toda, para lavar a cabeça pela manhã.

Desta forma, muitas mulheres acometidas pelo escalpelamento aprenderam com os seus próprios meios e sentidos a fortalecer o autocuidado do corpo.

Nesse processo ocorre uma hibridização de conhecimentos da medicina popular com a medicina tradicional, sendo valorizado o saber popular tal qual o da medicina de base científica e mercadológica.

Concordamos com Candau (2008) da necessidade de se reconhecer as especificidades que as múltiplas culturas abarcam, superando ao universalismo do discurso hegemônico da ciência moderna. Assim, a medicina popular elaborada pelas mulheres ribeirinhas acometidas pelo escalpelamento, são saberes que decolonizam os conhecimentos universalmente validos, fazendo-nos aprender com elas a sabedoria da medicina popular.

Por ser uma pessoa que teve o corpo mutilado, a mulher vitima de escalpelamento apresenta uma sensibilidade para compreender a pedagogia medicinal da floresta e para 
traduzir os diálogos que a sua corporeidade tece com os medicamentos naturais e os químicos. Por isso, se o bem-estar da natureza é preservado, para o bem-viver da própria comunidade.

Essa relação com a natureza e o bem-viver da mulher ribeirinha é expressa pela Amanacy, quando fala das garrafadas.

Para a mulherada eu faço garrafada. Tem a Verônica, o ipê, o jatobá, o acapu, barbatimão, saracura, são muitas. Ai, eu faço garrafada para as mulheres lá tomar. A garrafada é muito importante porque têm muitas mulheres que se queixam de dor de artrite, de dor de cadeira, de infecção de urina. Ai vai para o hospital e o médico passa remédio de farmácia, toma e não fica boa. E a garrafada, não. Você toma e fica boa. Eu tenho mais fé no remédio caseiro no que o da farmácia. Homem e criança podem tomar, também. Criança, se tiver infecção de urina, porque não é só gente grande que tem (COROACY-PORTO DE MOZ, 2018).

Há as garrafadas próprias para as mulheres e outras que homens e crianças podem tomar. Elas são utilizadas para diversos fins: artrite, infecção de urina, etc. Uma garrafada não é elaborada de maneira apática; há afeto, sentimento e altruísmo entre mulheres que conhecem as suas lutas biológicas e emocionais. Junto com o medicamente, vai o afeto, a amorosidade e o respeito.

Diferente da medicina ocidental, não há dicotomias entre as anatomias femininas e masculinas: o corpo humano se humaniza, ganha identidade, cultura e autonomia aos olhos das curandeiras ribeirinhas. Há uma subversão da medicina a partir do momento em que os medicamentos são compostos não apenas por ingredientes palpáveis como casas de frutas, plantas e seivas, mas por orações, diálogos e sensibilidades. Assim, há a preocupação em fomentar uma cura que não enxergue apenas o corpo, mas também o espírito.

Desta forma, são conhecimentos metodicamente catalogados na memória coletiva das comunidades ribeirinhas.

\section{d) O imaginário construído em comunidades ribeirinhas}

O imaginário também faz parte da cartografia de saberes das mulheres ribeirinhas. Este imaginário envolve narrativas míticas com grandes animais, seres encantados que vivem nos rios e nas matas. Expressam "a necessidade humana de registrar e transmitir uma descoberta, um conhecimento ou uma lição" (PEREIRA, 1994, p.19). 
A Iara narra sobre alguns entes do imaginário da Amazônia:

a cobra grande é imensa e ela fica pelo rio- o papai, inclusive, até já viu. Ele falou que ele viu, porque estava pescando ai eram umas 18 horas, ai ele viu tipo um porco, assim, bem grande, assim, em um miritizeiro no meio do rio. Ele olhou, parece que vinha só para próximo dele. Aí quando ele olhou bem mesmo viu que a cobra vinha andando. Ai, ele remou, vindo para casa. Quando ele olhou, sumiu (IARA-BREVES, 2018).

o pessoal da comunidade fala muito daquele bicho que se veste de gente, o lobisomem. Diz que tem na comunidade. Eu não brinco com isso, não. Eu fico espantada. O lobisomem sai de noite (ANGRA-BREVES, 2018).

tem um que é uma mistura de porco com gente. Muita gente conta que antes, quando na mata era mais deserto, no fim da tarde, duas pessoas viram. Chegaram na bicicleta. Ele rondava muito pela casa do meu pai e três horas da manhã ele estava capinando e viu ele. O meu pai, quando caçava, via muita coisa na floresta (CEUCI-VISEU, 2018).

O imaginário está mesclado à realidade social das comunidades ribeirinhas. Os seres encantados, ao desfilarem pelos rios e pelas matas, lembram que existe uma ecologia espacial (SANTOS, 2007), indicando que a realidade que conhecemos não se esgota, uma vez que coexiste com outros mundos com suas místicas e cosmogonias próprias que fogem da lógica ocidental.

Intercalando elementos da flora, da fauna e da personalidade humana, imagens lendárias como a cobra grande ensinam às mulheres ribeirinhas sobre o sentido pedagógico da pesca, da caça e do extrativismo, que não podem ser confundidos com atos ameaçadores sob a pena de represálias por parte das figuras mitológicas amazônicas guardiãs dos rios.

Oliveira, Mota-Neto e Souza (2007) explicam que há uma função educativa nas narrativas míticas porque mantém certa coesão entre os membros da comunidade, compartilhando elementos da tradição cultural local, bem como orienta as práticas sociais. Assim, ensina-se desde criança a respeitar a natureza, a cuidar dos recursos naturais, para não despertar a ira dos seres encantados.

As figuras do imaginário popular fazem parte do folclore amazônico e ganham novas representações a partir do lugar de fala das entrevistadas oriundas de distintas localidades ribeirinhas. Esta variedade de narrativas evidencia uma diversidade e riqueza cultural.

Ceuci narra sobre um personagem do imaginário amazônico, o Curupira. 
O Curupira já matou um homem, lá. Esse rapaz caçava e toda a vez ele tirava a roupa dele e subia. Ai, uma vez ele viu um menino negro, os olhos dele brilhavam e pegou toda a roupa dele e ele começou a ter uma dor de cabeça. O pessoal diz que o Curupira tem o pé para trás e o cabelo vermelho, mas não é assim, não. E esse rapaz que viu o Curupira ficou com uma dor de cabeça e não teve reza, não teve bênção, que desse jeito e ele morreu com essa dor de cabeça. Esse rapaz veio da mata gritando. Por isso que o Curupira não é assim como a gente conhece, não (CEUCI-VISEU, 2018).

A interpretação particular que Ceuci projeta sobre o Curupira, extremamente conhecido na literatura folclórica amazônica, atenta para a interculturalidade da Amazônia. Diferentes pontos de vista criam um imaginário híbrido. Por isso, há necessidade de se pensar no Curupira em uma perspectiva plural. Cada comunidade, a partir de suas vivências cosmogônicas singulares, empresta uma personalidade às lendas que se encontram nos registros orais.

Ela também relata a estória da rasga mortalha:

tem a estória da rasga mortalha que quando ela grita feio, o pai ou a mãe podem morrer. Ela tem um grito e faz um chiado e, com alguns dias, alguém vai morrer. E a cantiga dela, parece um som de quem está rasgando um pano. Pode prestar atenção. A rasga mortalha é um morcego grande, ela passa por cima da casa e grita (CEUCI-VISEU, 2018).

Ceuci em sua oralidade revela, inclusive, as distintas maneiras com que os povos da floresta decodificam a morte. É um universo no qual não há dicotomias entre o sagrado e o profano, o científico e o religioso e entre as dimensões sensíveis e inteligíveis, a morte adquire um verniz de complexidade totalmente enigmático para além de uma linha de raciocínio cartesiana.

Assim, vemos que a natureza se apresenta como uma religião viva. Uma espécie de conselheira, de bússola e de talismã atenta para os dilemas da carne e do espírito que sondam as comunidades ribeirinhas. O território amazônico deixa de ser uma simples poção geográfica, um apático desenho no mapa mundi para assumir sentidos simbólicos, afetivos, religiosos e culturais. 


\section{Considerações Finais}

O tamanho da diversidade cultural na Amazônia é proporcional aos desafios encarados por essa região. A realidade das mulheres ribeirinhas é um dos mais importantes emblemas das lutas políticas, econômicas e educativas que são travadas no território amazônico.

As mulheres ribeirinhas são mais vulneráveis a acidentes que provocam o escalpelamento e, por não afetar de maneira significativa os homens e as mulheres brancas, não é encarado como problema racial ou de gênero, o que reflete na política de prevenção que é realizada, em forma de campanhas nos meios de comunicação, sem resolver de forma definitiva esse tipo de acidente.

É nesse sentido que nunca foi tão emergencial pensar em uma educação comprometida com os direitos humanos. Um horizonte pedagógico que sem dúvida acena para o legado freireano. Essas mulheres possuem total consciência da violência social que sofrem como mulheres e pela violação a direitos basilares por elas vivenciados: como a ausência de educação e saúde dignas além de uma jurisprudência sensível às suas fragilidades cívicas como mulher.

Por isso, as pedagogias interculturais e decolonial ao se entrelaçarem ao pensamento freireano apontam para duas importantes questões: a) o reconhecimento das diferenças no seio de uma justiça social reconfigurada a partir das vozes das camadas populares e b) a tarefa de se descolonizar as mentes, reconhecendo os saberes culturais dos segmentos populares historicamente excluídos.

Não há dúvidas de que as mulheres ribeirinhas, ainda que se situem em um mesmo lugar de fala, apresentam filosofias, saberes e cosmogonias múltiplas, o que radicaliza ainda mais o sentido humanístico da categoria oprimido de Paulo Freire, que corresponde dialogicamente aos processos de ensino e de aprendizagem edificados por essas mulheres e que se rebelam contra as pedagogias eurocêntricas, racistas e patriarcais indicando que a escola tem muito a aprender com essas pescadoras, agricultoras, curandeiras e benzedeiras.

As dicotomias entre os saberes são dissolvidas a partir do momento em que os seus saberes não são subordinados à ciência ocidental para serem validados; o modelo científico eurocêntrico é desencantado, porque apresenta fissuras, sendo necessário se repensar a partir 
das vivências, místicas e cosmogonias de mulheres, que pensam não apenas com a mente, mas com o corpo sofrido e com a alma.

\section{REFERÊNCIAS}

ALVES, Raimundo Nonato Brabo. Características da agricultura indígena e sua influência na produção familiar da Amazônia. Belém: Embrapa, Amazônia Oriental, 2001.

AZEVEDO, James Ribeiro de. Tipologia do sistema de manejo de açaizais nativos praticados pelos ribeirinhos em Belém, estado do Pará. 113, f. Dissertação (Pós-graduação em Agriculturas Amazônicas da Universidade Federal do Pará)-Universidade Federal do Pará, 2005.

BRANDÃO, Carlos R. Em campo aberto. São Paulo: Cortez, 1995.

CANDAU, Vera Maria. Direitos humanos, educação e interculturalidade: as tensões entre igualdade e diferença. Rev. Bras. Educ, v.13, n.37, 2008. p.45-56.

CHISTÉ, Renan Campos; COHEN, Kelly de Oliveira; OLIVEIRA, Suzy Sarzi. Estudo das propriedades físico-químicas do tucupi. Ciência e tecnologia de alimentos, v.27, n.3, jul-set. 2017. p. 437- 40 .

DUSSEL, Enrique. 1492 - El encubrimiento del outro. Hacia el origen del mito de la modernidad. Conferencias de Frankfurt. Octubre. Madrid: Editorial Nueva Utopia. 1992.

FREIRE, Paulo. Pedagogia da autonomia: saberes necessários à prática educativa. 36e. São Paulo: Paz e Terra, 2007.

Educação \& atualidade brasileira. 2e. São Paulo: Cortez: Instituto Paulo Freire, 2001. $\overline{2000 .}$

Pedagogia da indignação: cartas pedagógicas e outros escritos. 6e. São Paulo: UNESP,

Política e educação. São Paulo: Cortez, 1993. 1981.

Ação cultural para a liberdade e outros escritos. 5 ed. Rio de Janeiro: Paz e Terra,

Cartas a Guiné-Bissau: registros de uma experiência em processo. 4e. Rio de Janeiro:

Paz e Terra, 1978.

GEERTZ, Clifford. A interpretação da cultura. Rio de Janeiro: Guanabara Koogan. S.A, 1989. 
QUIJANO, Aníbal. Colonialidad del poder y clasificación social. In CASTRO-GÓMEZ, Santiago; GROSFOGUEL Ramón (Eds.). El Giro Decolonial: Reflexiones para una diversidad epistémica más Allá del capitalismo global.Bogotá: Iesco-Pensar-Siglo del Hombre Editores, 2007.

HOOKS, Bell. Não sou uma mulher. Mulheres negras e feminismo. Rio de Janeiro: Plataforma Gueto, 1981.

LIMA, Adriane Raquel Santana de. Educação para mulheres e processo de descolonização da América Latina no Século XIX: Nísia Floresta e Soledad Acosta Samper, 262. Tese de doutorado (Programa de Pós-graduação em educação)-UFPA, 2016.

LÜDKE, Menga; ANDRÉ, Marli Elisa. Pesquisa em educação: abordagens qualitativas. São Paulo: E.P.U, 1986.

LOUREIRO, João de Jesus P. Cultura Amazônica: uma poética do imaginário. Belém: CEJUP, 1999.

MCLAREN, Peter. Rituais na escola: em direção a uma economia política de símbolos e gestos na educação. Petrópolis-Rio de Janeiro: Vozes, 1991.

RODRIGUES, Denise Simões; FRANÇA, M. D.P.A.D. Uso do documento em pesquisa sócio-histórica. In: MARCONDES, Maria Inês; OLIVEIRA, Ivanilde Apoluceno de. Metodologias técnicas de pesquisa em educação. Belém: UEPA, 2010.

MAIA, Angela Costa; BARRETO, Maíra. Violência contra crianças e adolescentes no Amazonas: análise dos registros. Psicologia em estudo. Maringá, v.17, n.2, p.195-204, abrjun. 2012.

MATHIS, Armin. Garimpo de ouro na Amazônia: atores sociais, relações de trabalho e condições de vida. Papers do NAEA, Abril. 1995.

MATTOS, P.L.P; FERREIRA FILHO, J.R; GOMES, J.C. Produção e preparo de manivassementes de mandioca. Cruz das Almas: Embrapa mandioca e fruticultura, 2003.

OLIVEIRA, Ivanilde Apoluceno de. Paulo Freire: gênese da educação intercultural no Brasil. Curitiba: CRV, 2015.

; MOTA-NETO, João Colares da. A construção de categorias de análise na pesquisa em educação. In: MARCONDES, Maria Inês; OLIVEIRA, Ivanilde Apoluceno; TEIXEIRA, Elizabeth (Orgs.). Abordagens teóricas e construções metodológicas na pesquisa em educação. Belém: EDUEPA, 2011. p. 167-186, 
; MOTA-NETO, João Colares da. Saberes da terra, da mata e das águas saberes culturais e educação. In: OLIVEIRA, Ivanilde Apoluceno (Orgs.). Cartografias ribeirinhas saberes e representações sobre práticas sociais cotidianas de alfabetizandos amazônidas. $2^{\mathrm{a}}$ ed. Belém: EDUEPA, 2008. p. 63-80.

Introdução. In: In: OLIVEIRA, Ivanilde Apoluceno (Orgs.). Cartografias ribeirinhas $\overline{\text { saberes }}$ e representações sobre práticas sociais cotidianas de alfabetizandos amazônidas. $2^{\mathrm{a}}$ ed. Belém: EDUEPA, 2008. p. 9-20.

; MOTA-NETO, João Colares; SOUZA, Roseane Rabelo. Saberes culturais, religiosidade e mitologia amazônica. In: OLIVEIRA, Ivanilde Apoluceno; SANTOS, Tânia Regina Lobato dos (Orgs). Cartografia dos saberes: representações sobre a cultura amazônica em práticas de educação popular. Belém: EDUEPA, 2007. p. 37-58.

PEREIRA, Franz Kreüther. Painel de lendas \& mitos da Amazônia. Belém, 1994.

PEREIRA, José Matias. O processo de ocupação e de desenvolvimento da Amazônia a implementação de políticas públicas e seus empregos para o meio ambiente. Brasília, n.34, abr/jun.1997.

QUEIROZ, Danielle Teixeira. et al. Observação participante na pesquisa qualitativa: conceitos e aplicações na área da saúde. Rev de enfermagem. Rio de Janeiro, v.15, n.2, p.27683. 2007.

SANTOS, Boaventura; MENESES, Maria Paula.(Org.) Epistemologias do Sul. São Paulo: Cortez, 2010.

A gramática do tempo para uma nova cultura política. 2.ed. São Paulo: Cortez, 2008. 2007.

Renovar a teoria crítica e reinventar a emancipação social. São Paulo: Boitempo,

A crítica da razão indolente: contra o desperdício da experiência. 4e. São Paulo:

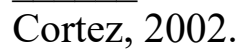

SOCORRO, do Andreza; SMITH, Pantoja de Oliveira. Tráfico de pessoas para exploração sexual. $1^{a}$ ed. Rio de Janeiro: Lumen Juris, 2017.

TRIVIÑOS, A.N.S. Introdução à pesquisa em ciências sociais: a pesquisa qualitativa em educação. São Paulo: Atlas, 1987.

\footnotetext{
${ }^{i}$ Mestre em Educação pelo Programa de Pós-Graduação em Educação e educadora do Núcleo de Educação Popular Paulo Freire da Universidade do Estado do Pará.
} 
E-mail: educadorauepa@gmail.com

ii Pós-Doutora em Educação pela PUC-RIO. Doutora em educação pela PUC-SP. Doutorado sanduiche na UNAM e UAM-Iztapalapa - México. Mestre em Educação Popular pela UFPB. Docente e pesquisadora do Programa de Pós-Graduação em Educação e coordenadora do Núcleo de Educação Popular Paulo Freire da Universidade do Estado do Pará.

E-mail: nildeapoluceno@uol.com.br

${ }^{i i i}$ Com o significado de atravessamentos e intercruzamentos de fronteiras.

iv Semente da mandioca (MATTOS; FERREIRA FILHO; GOMES, 2003).

${ }^{v}$ Massa que é fruto da mandioca triturada, prensada e torrada (CHISTÉ; COHEN; OLIVEIRA, 2007).

vi "a massa [da mandioca] prensada segue para a torração e o resíduo líquido, denominado de manipueira, é descartado ou transformado no tucupi. O tucupi é o molho parcialmente fermentado da manipueira (CHISTÉ; COHEN; OLIVEIRA, 2007, p.437). 